\title{
Amentoflavone triggers cell cycle G2/M arrest by interfering with microtubule dynamics and inducing DNA damage in SKOV3 cells
}

\author{
JINLI ZHANG ${ }^{1}$, AIGUO LI ${ }^{1}$, HANJING SUN ${ }^{2}$, XIFENG XIONG ${ }^{1}$, SHENGNAN QIN ${ }^{1}$, \\ PENGZHEN WANG ${ }^{1}$, LIBING DAI ${ }^{1}$, ZHI ZHANG ${ }^{3},{\text { XIAOJIAN } \text { LI }^{3} \text { and ZHIHE LIU }}^{1}$ \\ ${ }^{1}$ Guangzhou Institute of Traumatic Surgery; Departments of ${ }^{2}$ Traditional Chinese Medicine and ${ }^{3}$ Burn and Plastic Surgery, \\ Guangzhou Red Cross Hospital, Jinan University, Guangzhou, Guangdong 510220, P.R. China
}

Received August 12, 2019; Accepted July 14, 2020

DOI: $10.3892 / \mathrm{ol} .2020 .12031$

\begin{abstract}
Ovarian cancer is the seventh most common cancer and the second most common cause of cancer-associated mortality among gynecological malignancies worldwide. The combination of antimitotic agents, such as taxanes, and the DNA-damaging agents, such as platinum compounds, is the standard treatment for ovarian cancer. However, due to chemoresistance, development of novel therapeutic strategies for the treatment of ovarian cancer remains critical. Amentoflavone (AMF) is a biflavonoid derived from the extracts of Selaginella tamariscina, which has been used as a Chinese herb for thousands of years. A previous study demonstrated that AMF inhibits angiogenesis of endothelial cells and induces apoptosis in hypertrophic scar fibroblasts. In order to check the influence of AMF on cell proliferation, the effects of AMF on cell cycle and DNA damage were measured by cell viability, flow cytometry, immunofluorescence and western blotting assays in SKOV3 cells, an ovarian cell line. In the present study, treatment with AMF inhibited ovarian cell proliferation, increased $\mathrm{P} 21$ expression, decreased CDK1/2 expression, interrupted the balance of microtubule dynamics and arrested cells at the G2 phase. Furthermore, treatment with AMF increased the expression levels of phospho-Histone $\mathrm{H} 2 \mathrm{AX}(\gamma-\mathrm{H} 2 \mathrm{AX}$; a variant of histone 2A, that belongs to the histone $2 \mathrm{~A}$ family member $\mathrm{X}$ ) and the DNA repair protein RAD51 homolog 1 (Rad51), indicating the occurrence of DNA damage since $\gamma-\mathrm{H} 2 \mathrm{AX}$ and Rad51 are both key markers of DNA damage. Consistent with previous findings, the results of
\end{abstract}

Correspondence to: Dr Zhihe Liu, Guangzhou Institute of Traumatic Surgery, Guangzhou Red Cross Hospital, Jinan University, 396 Tongfu Zhong, Guangzhou, Guangdong 510220, P.R. China E-mail: zliu0731@163.com

Dr Xiaojian Li, Department of Burn and Plastic Surgery, Guangzhou Red Cross Hospital, Jinan University, 396 Tongfu Zhong, Guangzhou, Guangdong 510220, P.R. China

E-mail: lixj64@163.com

Key words: amentoflavone, cell cycle, DNA damage, microtubule dynamics the present study suggest that AMF is a potential therapeutic agent for the treatment of ovarian cancer. In addition, the effects of AMF on cell cycle arrest and DNA damage induction may be the molecular mechanisms by which AMF might exert its potential therapeutic benefits in ovarian cancer.

\section{Introduction}

According to statistics, the incidence rate of ovarian cancer in 2018 was $3.4 \%$, worldwide (1). Ovarian cancer is the eighth most common cancer in female and the second most common cause of cancer-associated mortality among gynecological malignancies worldwide (1). A combination of antimitotic agents, such as taxanes, and DNA-damaging agents, such as platinum compounds remains the principle treatment for ovarian cancer (2), whereby $60-85 \%$ of patients with high-grade ovarian cancer initially respond to this regimen; however, the majority of these patients eventually relapse due to chemoresistance $(3,4)$. Furthermore, most patients with high-grade ovarian cancer are resistant to paclitaxel and associated microtubule inhibitors $(3,4)$. Thus, development of novel therapeutic strategies for the treatment of ovarian cancer remains critical.

Several anticancer drugs exert their effects through the cell cycle. For example, methotrexate, vinca alkaloids and bleomycin play function by arresting cells in $\mathrm{S}$ phase or $\mathrm{G} 2 / \mathrm{M}$ phase. The cell cycle is a complex multi-step process that is regulated by different mechanisms, including cyclin-dependent kinase (CDK) pathways, metabolic adaptations and redox-dependent signaling. CDK complexes play key regulatory roles in cell cycle progression (5). In CDK-dependent pathways, the catalytic activities of CDKs are modulated by the interactions between cyclins and CDK inhibitors (CKIs) (6). In this progression, cyclins and CKIs serve as brakes to halt cell cycle progression under unfavorable conditions, such as when DNA damage is present (7). P21, a member of the cyclin-dependent kinase inhibition protein/kinase inhibition protein family of CKIs, is activated following DNA damage and metabolic stress, which arrests cell cycle progression in the G1/S and G2/M phases by inhibiting Cyclin D/CDK4 and CDK6, and Cyclin E/CDK2 activities, respectively (8).

In addition to cyclin-CDK complexes, several other cell cycle-associated targets exist for antitumor therapies. For 
example, taxanes and colchicine can also induce cell cycle arrest by influencing microtubule (MT) stability $(9,10)$. MTs are hollow cylindrical tubes consisting of 13 aligned protofilaments, formed from repeating $\alpha$-tubulin and $\beta$-tubulin heterodimers (11). MTs undergo polymerization and de-polymerization, while the dynamic balance between them plays a central role in cell meiosis. Disruption of this balance caused by factors, such as low temperature and drugs halts meiosis. Taxanes are MT regulators that block cell meiosis in $\mathrm{G} 2 / \mathrm{M}$ by binding to tubulin, thus promoting MT polymerization and eventually inducing apoptosis (12). In addition to directly affecting tubulin, MT regulators can also influence the expression of MT-associated proteins. For example, stathmin is a MT de-polymerizing protein that regulates MT dynamics and spindle assembly through binding to $\alpha / \beta$-tubulin heterodimers (13). The high expression level of stathmin decreased the sensitivity of ovarian cancer to paclitaxel (14). However, taxanes and anti-stathmin therapy produced a synergistic anticancer effect, and stathmin knockdown, by transfecting the expression construct containing full-length stathmin cDNA in the antisense orientation, increased taxanes sensitivity (15). A previous study has demonstrated that p53 induces cell arrest at the $\mathrm{G}_{2} / \mathrm{M}$ checkpoint by downregulating stathmin, while its expression is activated following DNA damage (16).

Plant-derived flavones, such as morelloflavone and ginkgo, have also been reported to play an important role in preventing cancer progression including prostate and lung cancer cells $(17,18)$. Amentoflavone (AMF) is a biflavonoid extracted from the Chinese herb Selaginella tamariscina, which displays several pharmacological properties, including antitumor, anti-inflammatory and antiviral effects (19-22). A previous study demonstrated that AMF inhibits angiogenesis of endothelial cells and induces apoptosis in hypertrophic scar fibroblasts (23). Although it has been demonstrated that AMF inhibits the development of different types of cancer, its underlying molecular mechanisms in ovarian cancer remain unclear.

Thus, the present study aimed to investigate the effect of AMF on ovarian cancer progression and the underlying mechanisms involved in the observed effects. The results demonstrated that AMF decreased ovarian cancer cell viability and induced cell cycle arrest, by disrupting the balance of MT dynamics and increasing the levels of DNA damage. Taken together, the results of the present study suggest that AMF may act as a therapeutic agent in the treatment of ovarian cancer.

\section{Materials and methods}

Cell culture, cell line and reagents. The SKOV3 human ovarian cancer cell line was purchased from the Cell Bank of Type Culture Collection of the Chinese Academy of Sciences. Cells were maintained in DMEM supplemented with $10 \%$ FBS, 2 mM glutamine (all from Thermo Fisher Scientific, Inc.), 100 units of penicillin $/ \mathrm{ml}$ and $100 \mu \mathrm{g}$ of streptomycin $/ \mathrm{ml}$ (both from Corning Life Sciences) at $37^{\circ} \mathrm{C}$ in a humidified atmosphere of $5 \% \mathrm{CO}_{2}$ and subcultured every 2-3 days. AMF was purchased from Shanghai Winherb Medical Science Co. Ltd., with a purity of $99 \%$. A total of $100 \mathrm{mmol} / \mathrm{l}$ stock solution of AMF was prepared in dimethyl sulfoxide (Sigma-Aldrich; Merck KGaA) and stored at $-20^{\circ} \mathrm{C}$ until further experimentation.
Cell viability assay. SKOV3 cells were seeded in 96-well plates at a density of 5,000 cells/well $(100 \mu \mathrm{l})$. After $24 \mathrm{~h}$, cells were treated with different concentrations of AMF $(0,50,75,100,150$ and $200 \mu \mathrm{mol} / 1)$ for $48 \mathrm{~h}$ at $37^{\circ} \mathrm{C}$. Cell viability was determined via the CellTiter 96 Aqueous One Solution Proliferation assay (Promega Corporation) at a wavelength of $490 \mathrm{~nm}$, using a multi-well spectrophotometer (Agilent Technologies, Inc.). All experiments were performed in triplicate.

Flow cytometric analysis. A total of $1 \times 10^{5}$ SKOV3 cells/well were seeded in 6-well overnight and treated with different concentrations of $\operatorname{AMF}(0,100$ and $150 \mu \mathrm{mol} / 1)$ for $48 \mathrm{~h}$ at $37^{\circ} \mathrm{C}$. Cells were fixed in $70 \%$ ethanol overnight at $4^{\circ} \mathrm{C}$, permeabilized with $0.1 \%$ Triton X-100 (Sigma-Aldrich; Merck KGaA), digested with RNaseA (Thermo Fisher Scientific, Inc.) and subsequently stained with propidium iodide (BD Biosciences) in the dark for $30 \mathrm{~min}$ at $37^{\circ} \mathrm{C}$, prior to cell cycle analysis using a FACS Calibur flow cytometer (BD Biosciences) and analyzed using ModFit LT Windows 3.2 (Verity Software House, Inc.).

Immunofluorescence. A total of $1 \times 10^{4} \mathrm{SKOV} 3$ cells/well were seeded onto coverslips in a six-well plate. Following incubation for $24 \mathrm{~h}$ at $37^{\circ} \mathrm{C}$, cells were treated with different concentrations of $\operatorname{AMF}(0,100$ and $150 \mu \mathrm{mol} / \mathrm{l})$ for $48 \mathrm{~h}$ at $37^{\circ} \mathrm{C}$. Subsequently, cells were fixed with $4 \%$ paraformaldehyde for $15 \mathrm{~min}$ at room temperature, permeabilized with $0.25 \%$ Triton $\mathrm{X}-100$ for $10 \mathrm{~min}$ and blocked with $1 \%$ BSA for $30 \mathrm{~min}$ at room temperature. Cells were incubated with primary antibodies against phospho-Histone $\mathrm{H} 2 \mathrm{AX}(\gamma-\mathrm{H} 2 \mathrm{AX} ; 1: 200 \mathrm{v} / \mathrm{v}$; cat. no. 9718), $\alpha$-tubulin (1:200 v/v; cat. no. 2144) or $\beta$-tubulin (1:200 v/v; cat. no. 2146), all from Cell Signaling Technology Inc., overnight at $4^{\circ} \mathrm{C}$. Subsequently, cells were incubated with Alexa Fluor 488-labeled goat anti-rabbit secondary antibody (1:500 v/v; cat. no. 4416; Cell Signaling Technology, Inc.) for $1 \mathrm{~h}$ at room temperature. Nuclei were stained with $0.1 \mu \mathrm{g} / \mathrm{ml}$ DAPI (Santa Cruz Biotechnology Inc.) for $5 \mathrm{~min}$ at room temperature. Cell images were observed under a Nikon Eclipse E600 fluorescence microscope (magnification, x400; Nikon Corporation) and analyzed using NIS-Elements D 4.50 software (Nikon Corporation).

Western blotting. A total of $1 \times 10^{5}$ SKOV3 cells/well were seeded into 100-mm cell culture dishes and treated with different concentrations of $\operatorname{AMF}(0,100$ and $150 \mu \mathrm{mol} / \mathrm{l})$ for $48 \mathrm{~h}$ at $37^{\circ} \mathrm{C}$. Total protein was extracted using RIPA lysis buffer $(150 \mathrm{mM} \mathrm{NaCl}, 50 \mathrm{mM}$ Tris with $\mathrm{pH} 7.4,1 \% \mathrm{NP} 40$, $0.1 \%$ SDS and $0.5 \%$ sodium deoxycholate; Beyotime Institute of Biotechnology) supplemented with $10 \mathrm{mM}$ phenylmethanesulphonyl fluoride (Amresco, Inc.) and 10X phosphatase inhibitor (Roche Applied Science). Total protein concentration was determined using the bicinchoninic acid protein assay kit (Thermo Fisher Scientific, Inc.), $20 \mu \mathrm{g}$ protein samples per lane were loaded and separated via 10\% SDS-PAGE and electroblotted. The separated proteins were subsequently transferred onto polyvinylidene difluoride membranes (Merck KGaA) and blocked with $5 \%(\mathrm{w} / \mathrm{v})$ non-fat milk powder in TBST [10 mM Tris, pH 7.5, $150 \mathrm{mM} \mathrm{NaCl}$ and $0.1 \%$ (v/v) Tween 20] for $2 \mathrm{~h}$ at room temperature. Membranes were incubated with primary antibodies against GAPDH (1:1,000 v/v; cat. no. 2118; 
Cell Signaling Technology Inc.), $\beta$-tubulin $(1: 1,000 \mathrm{v} / \mathrm{v}$; cat. no. 2146; Cell Signaling Technology Inc.), Cyclin-B1 (1:1,000 v/v; cat. no. 12231; Cell Signaling Technology Inc.), CDK2 (1:1,000 v/v; cat. no. ab32147; Abcam), p-CDK1 (1:1,000 v/v; cat. no. 4539; Cell Signaling Technology Inc.), P21 (1:1,000 v/v; cat. no. 2947; Cell Signaling Technology Inc.), $\gamma$-H2AX (1:1,000 v/v; cat. no. 9718; Cell Signaling Technology Inc.), stathmin $(1: 1,000 \mathrm{v} / \mathrm{v}$; cat. no. ab52630; Abcam), Rad51 $(1: 1,000 \mathrm{v} / \mathrm{v}$; cat. no. ab133534; Abcam) or CDK1 $(1: 1,000 \mathrm{v} / \mathrm{v}$; cat. no. ab18; Abcam) overnight at $4^{\circ} \mathrm{C}$. The membranes were washed three times with TBST and subsequently incubated with horse radish peroxidase-conjugated secondary antibodies $(1: 2,000 \mathrm{v} / \mathrm{v}$; cat. no. 7074 or 7076 ; Cell Signaling Technology Inc.) diluted in TBST for $1 \mathrm{~h}$ at room temperature. Membranes were re-washed three times with TBST, and protein bands were visualized using the electrochemiluminescence detection kit (Pierce; Thermo Fisher Scientific, Inc.) and imaged using the ChemiDoc XRS+ Imaging System (Bio-Rad Laboratories, Inc.). Image Lab 3.0 software (Bio-Rad Laboratories, Inc.) was used for semi-quantitative analysis of band signals.

Statistical analysis. Statistical analysis was performed using SPSS software v17.0 (IBM Corp.) and data are presented as the mean + standard deviation (SD) of at least three independent experiments. One-way analysis of variance and Student-Newman-Keuls post-hoc test were used to compare difference between multiple groups. Unpaired Student's t-test was used to test statistical significance between two groups. $\mathrm{P}<0.05$ was considered to indicate a statistically significant difference.

\section{Results}

AMF inhibits SKOV3 cell viability. The effect of AMF on SKOV3 cell viability was assessed via the CellTiter 96 Aqueous One Solution Proliferation assay. Cells were treated with different concentrations of AMF (50-200 $\mu \mathrm{mol} / \mathrm{l})$ for $48 \mathrm{~h}$. The results demonstrated that AMF significantly inhibited SKOV3 cell viability in a dose-dependent manner, from $75 \mu \mathrm{mol} / 1$ onwards compared with the control cells (Fig. 1A).

AMF induces $S$ phase and $G 2$ cell cycle arrest of SKOV3 cells. In order to determine the molecular mechanism underlying the inhibitory effect of AMF on SKOV3 cell viability, the effect of AMF on the cell cycle was assessed. SKOV 3 cells were treated with 100 or $150 \mu \mathrm{mol} / 1 \mathrm{AMF}$ for $48 \mathrm{~h}$ and flow cytometric analysis was performed to determine cell cycle distribution. The results demonstrated that treatment with AMF slightly increased the percentage of SKOV3 cells in the $\mathrm{S}$ or $\mathrm{G}_{2}$ phases, and decreased the percentage of SKOV 3 cells in the $\mathrm{G}_{1}$ phase (Fig. 1B and C). Comparing with the percentage of SKOV3 $G_{1}$ or $G_{2}$ phase cells in the control group, the percentage of $\mathrm{G}_{1}$ phase cells in $150 \mu \mathrm{mol} / 1$ AMF group was significantly decreased, while the percentages of $\mathrm{G}_{2}$ phase cells in 100 and $150 \mu \mathrm{mol} / \mathrm{l}$ AMF groups were significantly increased. Taken together, these results suggest that AMF arrests cell cycle at the $\mathrm{G} 2$ phase and interferes with cell meiosis and cell proliferation.

AMF regulates the expression of cell cycle-associated proteins in SKOV3 cells. In order to further investigate the molecular mechanisms by which AMF arrests the cell cycle, the effect of AMF on the expression levels of proteins associated with cell cycle progression was assessed via western blot analysis. The expression levels of p-CDK1 and CDK 2 decreased in SKOV3 cells treated with 100 or $150 \mu \mathrm{mol} / 1$ AMF for $48 \mathrm{~h}$ (Fig. 1D and E). Furthermore, CDK1 expression decreased in SKOV3 cells treated with 100 and $150 \mu \mathrm{mol} / \mathrm{l} \mathrm{AMF}$; however, a significant decrease was only observed in the cells treated with $150 \mu \mathrm{mol} / 1$ of AMF (Fig. 1D and E). The p-CDK1/CDK1 ratio decreased in cells treated with AMF; however, no significant differences were observed compared with the control cells (Fig. 1D and E). Notably, cyclin B1 expression was significantly downregulated in SKOV3 cells treated with $100 \mu \mathrm{mol} / 1 \mathrm{AMF}$ and upregulated in cells treated with $150 \mu \mathrm{mol} / \mathrm{l} \mathrm{AMF.} \mathrm{P21,} \mathrm{a}$ well-known inhibitor of the cell cycle, significantly increased in AMF-treated cells compared with AMF-untreated ovarian cells (Fig. 1E).

AMF interferes with tubulin expression and spindle assembly. MTs are made from tubulin heterodimers and are vital for several cellular processes, such as spindle assembly for cell meiosis (24). MTs have complex polymerization characteristics and are stable and long lasting during interphase (25). Conversely, MTs become short and dynamic during mitosis. Stathmin regulates cell cycle progression by influencing the dynamics of MTs (13).

The present study assessed the influence of AMF on MT structure via immunofluorescent staining of $\alpha / \beta$-tubulin in SKOV3 cells, and determined the expression levels of stathmin and $\beta$-tubulin via western blot analysis. Immunofluorescence staining demonstrated that $\alpha / \beta$-tubulin were long and condensed in AMF-treated cells compared with the control cells (Fig. 2A and B). Furthermore, the expression levels of $\beta$-tubulin and stathmin were significantly downregulated following treatment with AMF (Fig. 2C and D). Taken together, these results indicate that spindle assembly and cell meiosis are altered in AMF-treated SKOV3 cells.

AMF induces DNA damage in SKOV3 cells. In order to determine whether AMF induces DNA damage in SKOV3 cells, the expression levels of $\gamma-\mathrm{H} 2 \mathrm{AX}$, a specific marker of DNA double-strand breaks (DSBs) (26), were assessed via immunofluorescence and western blot analyses. Immunofluorescence staining demonstrated that the percentage of $\gamma$-H2AX-positive cells significantly increased in AMF-treated SKOV3 cells compared with the control cells (Fig. 3A and B). Furthermore, the number of DNA-damaged cells and fluorescence intensity increased with AMF in a dose-dependent manner. Compared with in the control cells, western blot analysis indicated that the protein expressions were significantly higher in 100 and $150 \mu \mathrm{mol} / 1 \mathrm{AMF}-$ treated cells for $\gamma-\mathrm{H} 2 \mathrm{AX}$ and in $150 \mu \mathrm{mol} / 1$ AMF-treated cells for Rad51 (Fig. 3C and D). Taken together, these results suggest that AMF induces extensive DNA damage. Rad51 formation is a hallmark of homologous recombination repair (HRR), which is often induced by DNA damage (27). The results of the present study indicated that DSBs were induced by AMF and the cells attempted to repair DNA damage through the HRR signaling pathway. 
A

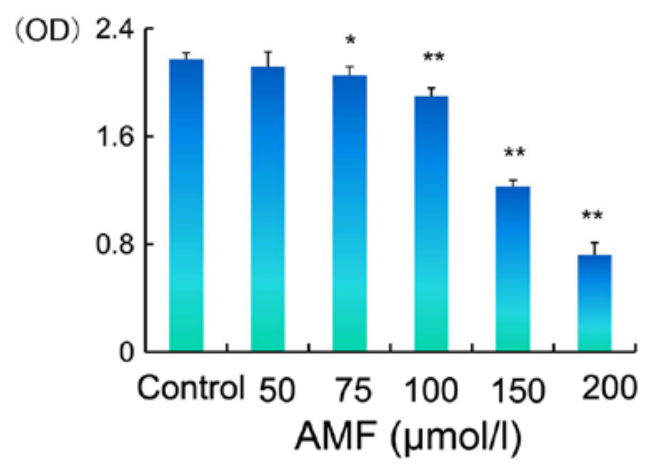

$\mathrm{B}$

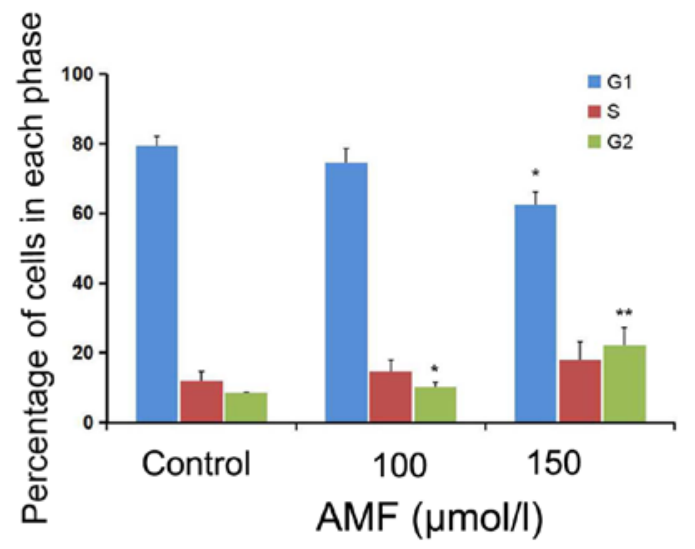

C

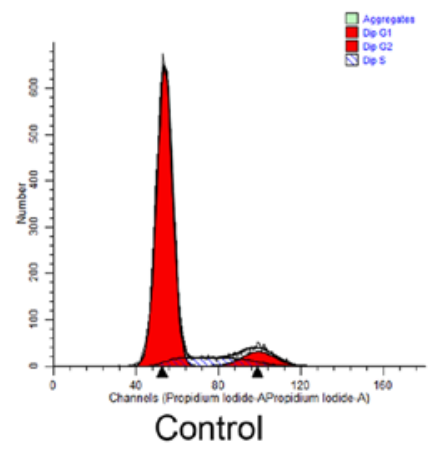

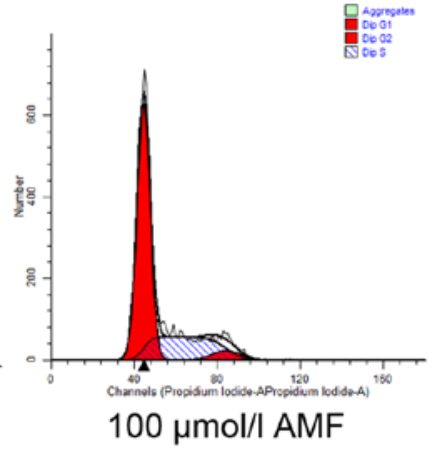

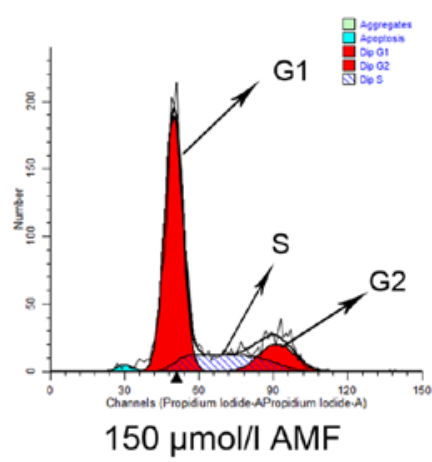

E
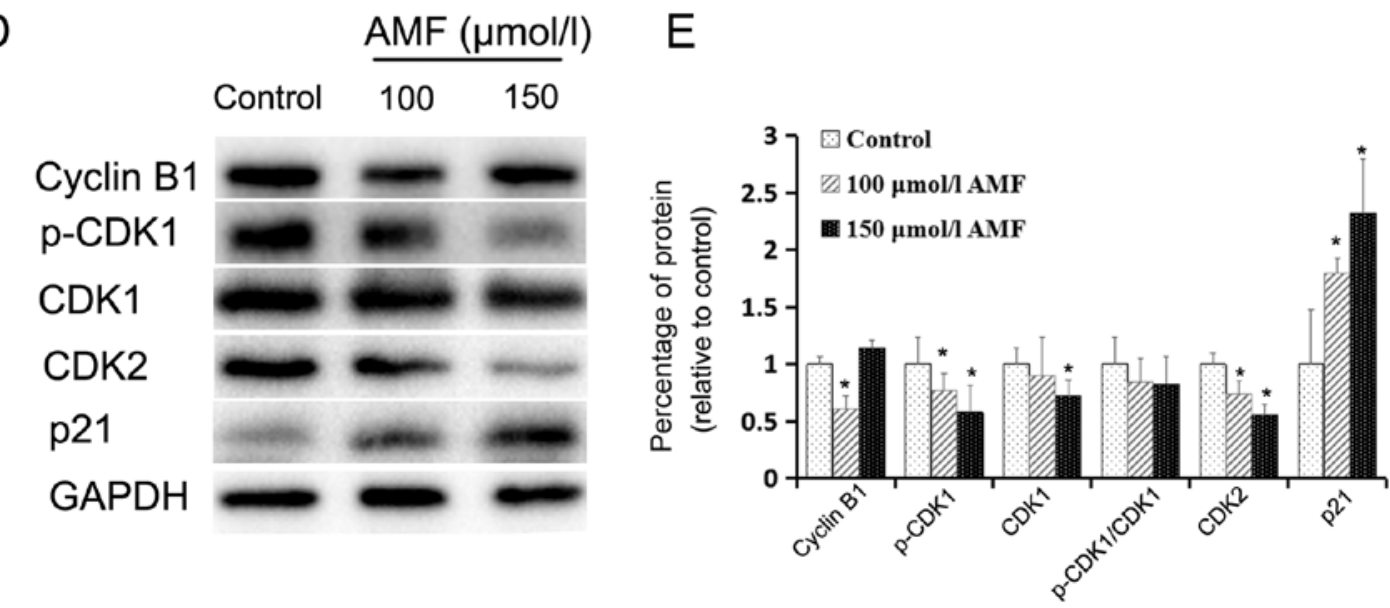

Figure 1. AMF decreases SKOV3 cell viability and induces cell cycle arrest. (A) SKOV3 cells were treated with different concentrations $(0,5075,100,150$ and $200 \mu \mathrm{mol} / \mathrm{l}$ ) of AMF for $48 \mathrm{~h}$ and cell viability was assessed via the CellTiter 96 Aqueous One Solution Proliferation assay. The results demonstrated that AMF decreased SKOV3 cell viability in a dose-dependent manner. (B) Histograms showed the cell cycle distribution at G1, S and G2 phase. Data are presented as the mean $\pm \operatorname{SD}(\mathrm{n}=3)$. SKOV3 cells were treated with different concentrations of AMF $(0,100$ and $150 \mu \mathrm{mol} / \mathrm{l})$ for $48 \mathrm{~h}$ and cell cycle distribution was assessed via flow cytometric analysis. (C) Cell cycle analysis by flow cytometry. SKOV3 cells were treated with different concentrations of AMF ( 0,100 and $150 \mu \mathrm{mol} / \mathrm{l})$ for $48 \mathrm{~h}$. (D) The expression levels of cyclin B, p-CDK1, CDK1, CDK2 and p21 were determined in SKOV3 cells treated with different concentrations of $\operatorname{AMF}(0,100$ and $150 \mu \mathrm{mol} / 1)$ for $48 \mathrm{~h}$ by western blot. GAPDH was used as the loading control. (E) Protein expression levels from the western blot in (D) relative to the GAPDH control. Data are presented as the mean $\pm \mathrm{SD}(\mathrm{n}=3)$. ${ }^{*} \mathrm{P}<0.05,{ }^{* * *} \mathrm{P}<0.01$ vs. control. AMF, amentoflavone; SD, standard deviation; CDK, cyclin-dependent kinase.

\section{Discussion}

Previous studies have reported the anticancer effects of AMF in different types of tumor (28-32). For example, AMF has been demonstrated to be associated with apoptosis and the inhibition of metastasis and angiogenesis of tumors. Furthermore, AMF has exhibited its anticancer effect in $\mathrm{SiHa}$ and CaSki cervical cancer cells by the suppressing expression levels of the human papilloma virus protein, E7 (33). The present study investigated the antitumor effect of AMF on ovarian cancer, and the results demonstrated that AMF decreased SKOV3 cell viability and induced cell cycle arrest in the S and G2 phases, in a dose-dependent manner. Furthermore, AMF induced DNA damage and interfered with MT function and meiosis. 

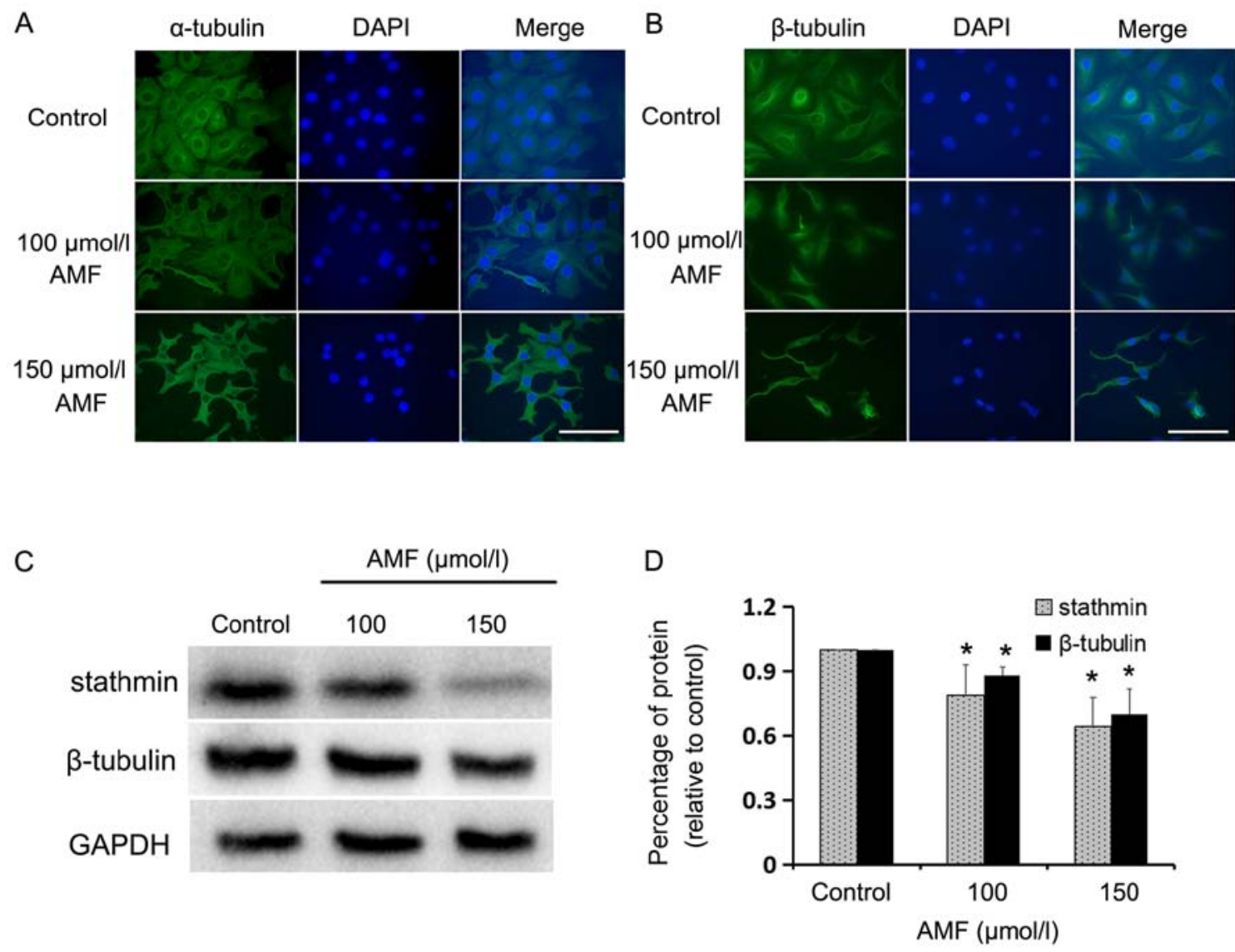

Figure 2. AMF interferes with tubulin expression and spindle assembly. (A) Immunofluorescence staining of $\alpha$-tubulin (green) in SKOV3 cells treated with different concentrations of AMF for $48 \mathrm{~h}$. Nuclei (blue) were stained with DAPI (magnification, $\mathrm{x} 400$; scale bar, $100 \mu \mathrm{m}$ ). (B) Immunofluorescence staining of $\beta$-tubulin (green) in SKOV3 cells treated with different concentrations of AMF for 48 h. Nuclei (blue) were stained with DAPI (magnification, $\mathrm{x} 400$; scale bar, $100 \mu \mathrm{m})$. (C) The expression levels of stathmin and $\beta$-tubulin in SKOV3 cells treated with different concentrations of AMF, via western blot analysis. GAPDH was used as the loading control. (D) Protein expression levels from the western blot in (C) relative to the GAPDH control. Data are presented as the mean \pm standard deviation $(\mathrm{n}=3)$. ${ }^{*} \mathrm{P}<0.05$ vs. control. AMF, amentoflavone.

Several antitumor drugs, such as paclitaxel and cisplatin, decrease cell proliferation by either inducing cell death or arresting cell cycle progression. Previous studies have reported that AMF induces cell apoptosis $(23,32,33)$. The results of the present study demonstrated that treatment with AMF significantly increased the proportion of G2 phase SKOV3 cells. The proportion of S phase cells was also upregulated, however, no significant difference was observed compared with the control cells. The results of the present study demonstrated that AMF was able to induce cell cycle arrest of ovarian cancer cells in $\mathrm{S}$ and G2 phases, which is in partly inconsistent with previous findings that have demonstrated that AMF is able to arrest cells either in S or G1 phases (34-36). These results suggest that the effect of AMF on cell cycle is influenced by cell type, AMF concentration or/and treatment time. There are some AMF-like bioflavonoids, such as bilobetin, isoginkgetin and morelloflavone, which can also arrest cell cycle at $\mathrm{G}_{2} / \mathrm{M}$ phase by inducing cell apoptosis or inhibiting the activation of Raf/MEK/ERK kinases (18). It is well known that CDKs, CKIs and cyclins also play key roles in cell cycle progression $(6,37,38)$. CDK1, in combination with cyclin $A$ and $B$, regulates the transition from $G_{2}$ to $M$ phase (39). P21, a member of the CKIs, can promote cell cycle arrest as a response to several stimuli such as DNA damage and oxidative stress by regulating $\mathrm{G}_{1} / \mathrm{S}$ or $\mathrm{G}_{2} / \mathrm{M}$ transitions, respectively (8). P21 is predominantly induced by $\mathrm{p} 53$, which is activated by several stressors, including DNA damage. P21 is also known to inhibit the activity of cyclin A/CDK1/2, which results in cell cycle arrest in the $S$ phase $(40,41)$. In the present study, the expression levels of p-CDK1 and CDK2 significantly decreased, while P21 expression increased in AMF-treated SKOV3 cells, suggesting that $A M F$ may induce $\mathrm{G}_{2} / \mathrm{M}$ cell cycle arrest by upregulating P21 and downregulating CDK1 and CDK2. A previous study demonstrated that paclitaxel or eribulin can arrest cell meiosis and lead to the accumulation of mitotic marker proteins, such as cyclin B1 (42). In the present study, cyclin B1 was significantly downregulated following treatment with $100 \mu \mathrm{mol} / 1 \mathrm{AMF}$, but upregulated following treatment with $150 \mu \mathrm{mol} / \mathrm{l} \mathrm{AMF}$. A reason for this increase in cyclin B1 expression may be due to the protein accumulation induced by meiosis arrest.

MT acts as a key drug target in tumor cells due to its roles in determining and supporting cell shape, cell division, transport and signal transduction (43). Previous studies have demonstrated that paclitaxel or eribulin can arrest cell meiosis by regulating MT polymerization $(12,44,45)$. Under normal conditions, there is a balance between polymerization and de-polymerization of MTs, whereby 
A

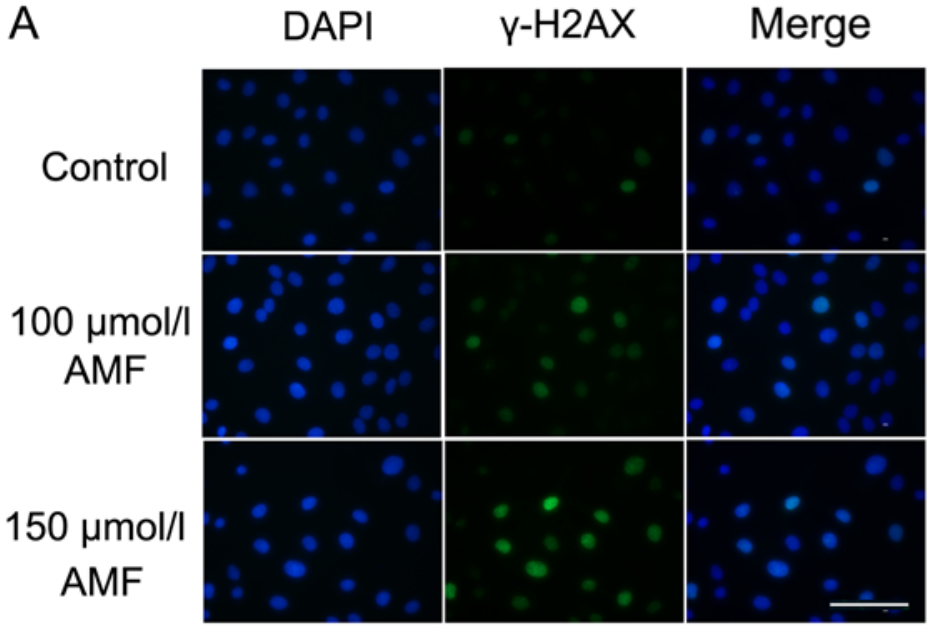

B

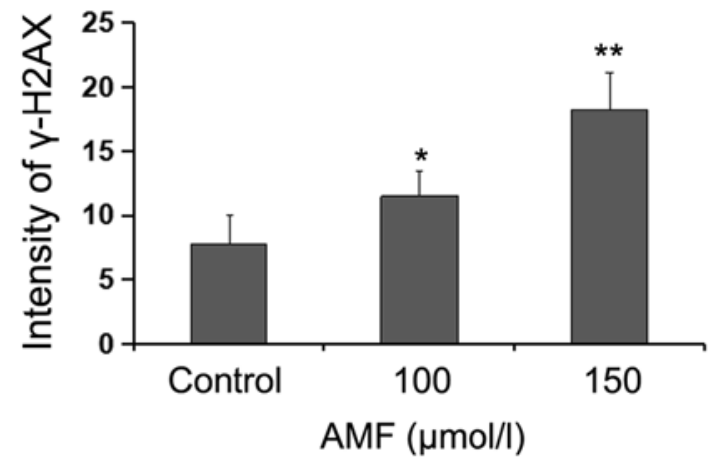

C

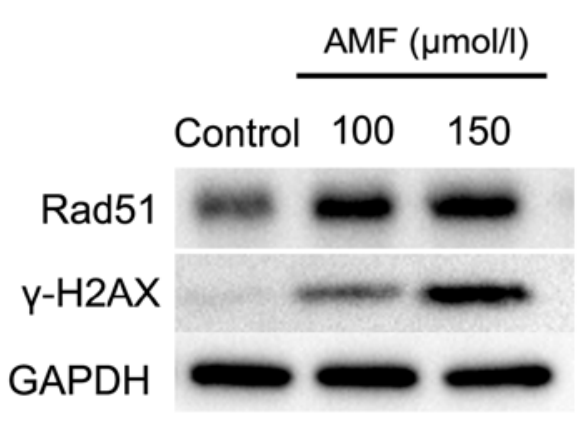

D

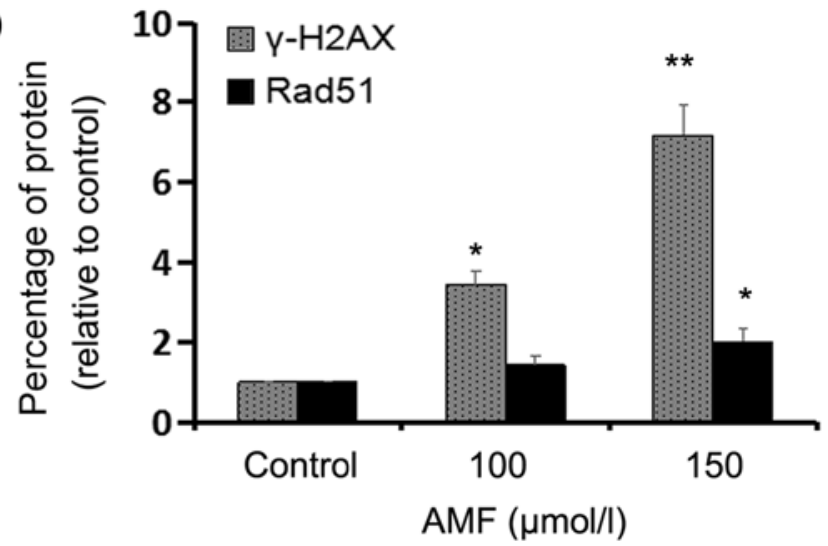

Figure 3. AMF induces DNA damage in SKOV3 cells. (A) Immunofluorescence staining of nuclei (blue) and $\gamma$-H2AX (green) in SKOV3 cells treated with different concentrations of AMF for $48 \mathrm{~h}$ (magnification, $\mathrm{x} 400$; scale bar, $100 \mu \mathrm{m}$ ). (B) Fluorescence intensities of $\gamma$-H2AX in SKOV3 cells treated with different concentrations of AMF for $48 \mathrm{~h}$. Data are presented as the mean \pm SD $(n=3)$. (C) Expression levels of $\gamma-\mathrm{H} 2 \mathrm{AX}$ and Rad51 in SKOV3 cells treated with different concentrations of AMF, via western blot analysis. GAPDH was used as the loading control. (D) Protein expression levels from the western blot in (C) relative to the GAPDH control. Data are presented as the mean $\pm \mathrm{SD}(\mathrm{n}=3) .{ }^{*} \mathrm{P}<0.05,{ }^{* *} \mathrm{P}<0.01$ vs. control. AMF, amentoflavone; $\gamma-\mathrm{H} 2 \mathrm{AX}$, phospho-Histone $\mathrm{H} 2 \mathrm{AX}$; $\mathrm{SD}$, standard deviation.

disruption of this balance destroys the normal MT structures observed $(46,47)$. Stathmin is a MT destabilizing protein that inhibits tubulin dimer polymerization and contributes to the formation of cell spindles (48). Previous studies have reported that stathmin is upregulated in the highly malignant types of breast and ovarian cancers $(49,50)$. Furthermore, downregulation of stathmin inhibits cell viability and induced apoptosis in several types of cancer cells $(51,52)$. Paclitaxel is an efficacious MT-stabilizing antitumor drug, particularly used in the treatments of ovarian, breast and non-small cell lung cancers (53). Paclitaxel is considered to shift the assembly equilibrium of MTs towards the depolymeric state, thus blocking cell entry into meiosis by suppressing MT dynamics (53). The results of the present study demonstrated that treatment with AMF decreased the expression levels of stathmin and $\beta$-tubulin in SKOV3 cells. Immunofluorescence staining was performed to assess MT structures, using antibodies against $\alpha$ - and $\beta$-tubulin. The results indicated that MT structures were distorted, and the cell spindle-like structures were disturbed following treatment with AMF. Furthermore, AMF blocked cell cycle at the G2/M phase, interfered with MT dynamics and downregulated the expression levels of proteins associated with MT structures. Taken together, these results indicate that the effects of AMF on ovarian cancer cells are like those of paclitaxel.

Following cell DNA damage, DNA repair mechanisms are activated and DNA replication and meiosis are interrupted. Mammalian cells have evolved a series of DNA repair systems, including non-homologous end-joining and homologous recombination (HR) (54). $\mathrm{H} 2 \mathrm{AX}$, a variant of $\mathrm{H} 2 \mathrm{~A}$, is rapidly phosphorylated at Ser 139 and accumulates at DSB sites with other proteins including Rad51 and BRCA1/2 $(55,56)$. Among these, Rad51 is a key factor involved in $\operatorname{HR}(57,58)$. $\operatorname{Rad} 51$ is recruited to $\gamma-\mathrm{H} 2 \mathrm{AX}$ sites and polymerizes at the resection-generated single-stranded DNA ends, which leads to invasion and exchange between homologous DNA sequences (58). The results of the present study demonstrated that Rad51 expression markedly increased in AMF-treated SKOV3 cells. Furthermore, the intensity and expression of $\gamma$-H2AX were significantly upregulated in AMF-treated SKOV3 cells. Considering the key roles $\gamma$-H2AX and Rad51 play in DNA damage repair, the results of the present study suggest that AMF induces DNA damage and activates the HR 
repair system in AMF-treated SKOV3 cells. The present study demonstrated that AMF triggered cell cycle $\mathrm{G} 2 / \mathrm{M}$ arrest and induced DNA damage in ovarian cancer cells, even though it may be better to use several ovarian cancer cell lines than just to use SKOV3 cell line. We will be aimed at confirming these findings and prove the antitumor effect of AMF in ovarian cancer cell line derived xenograft mouse models.

In conclusion, the results of the present study demonstrated that AMF inhibited human ovarian cancer cell proliferation by triggering cell cycle arrest at the $\mathrm{G}_{2} / \mathrm{M}$ phase. Furthermore, AMF was demonstrated to interfere with MT dynamics and induce DNA damage. Thus, AMF may act as an antitumor drug by exerting its effects on MT dynamics and inducing DNA damage.

\section{Acknowledgements}

Flow cytometry work was supported by Ms. Fang Su and Ms. Jing Wei (Guangdong Provincial Key Laboratory of Malignant Tumor Epigenetics and Gene Regulation, Sun Yat-Sen Memorial Hospital, Sun Yat-Sen University, China).

\section{Funding}

The present study was funded by Guangdong Bureau of Traditional Chinese Medicine (grant nos. 20181206 and 20191260), the National Natural Science Foundation of China (grant no. 81272222 and 81902802), the General Science and Technology Project of Guangzhou Municipal Health Commission (grant no. 20181A010017 and 20191A011019), the Medical Science and Technology Research Foundation of Guangdong (grant nos. B2016018 and A2018063) and the Guangzhou Science and Technology Program Key Project (grant no. 201704020145).

\section{Availability of data and materials}

All data generated or analyzed during this study are included in this published article.

\section{Authors' contributions}

ZL, JZ, AL and XL contributed to the initial conception and design of the experiments. HS, XX, SQ, PW and LD performed the experiments. ZL and JZ wrote the paper. $\mathrm{ZZ}$ revised the experimental design and analyzed the data. All authors read and approved the final manuscript.

\section{Ethics approval and consent to participate}

Not applicable.

\section{Patients consent for publication}

Not applicable.

\section{Competing interests}

The authors declare that they have no competing interests.

\section{References}

1. Bray F, Ferlay J, Soerjomataram I, Siegel RL, Torre LA and Jemal A: Global cancer statistics 2018: Globocan estimates of incidence and mortality worldwide for 36 cancers in 185 countries. CA Cancer J Clin 68: 394-424, 2018.

2. Bookman MA: Optimal primary therapy of ovarian cancer. Ann Oncol 27 (Suppl 1): i58-i62, 2016.

3. Zhang X, Xu B, Sun CY, Wang LM and Miao X: Knockdown of CIP2A sensitizes ovarian cancer cells to cisplatin: An in vitro study. Int J Clin Exp Med 8: 16941-16947, 2015.

4. Damia G and Broggini M: Platinum resistance in ovarian cancer: Role of DNA repair. Cancers (Basel) 11: 119, 2019.

5. Dia-Moralli S, Tarrado-Castellarnau M, Miranda A and Cascante M: Targeting cell cycle regulation in cancer therapy. Pharmacol Ther 138: 255-271, 2013.

6. Lim S and Kaldis P: Cdks, cyclins and CKIs: Roles beyond cell cycle regulation. Development 140: 3079-3093, 2013.

7. Morgan DO: The cell cycle: Principles of control. Primers in biology, New Science, 2007.

8. Karimian A, Ahmadi Y and Yousefi B: Multiple functions of p2 in cell cycle, apoptosis and transcriptional regulation after DNA damage. DNA Repair (Amst) 42: 63-71, 2016.

9. Liebmann J, Cook JA, Lipschultz C, Teague D, Fisher J and Mitchell JB: The influence of Cremophor EL on the cell cycle effects of paclitaxcl (Taxol) in human tumor cell lines. Cancer Chemother Pharmacol 33: 331-339, 1994.

10. Jordan MA, Toso RJ, Thrower D and Wilson L: Mechanism of milotic block and inhibition of cell proliferation by taxol at low concentrations. Proc Nati Acad Sci USA 90: 9552-9556, 1993.

11. Desai A and Mitchison TJ: Microtubule polymerization dynamics. Annu Rev Cell Dev Biol 13: 83-117, 1997.

12. Schiff PB, Fant J and Horwitz SB: Promotion of microtubule assembly in vitro by taxol. Nature 277: 665-667, 1979.

13. Charbaut E, Curmi PA, Ozon S, Lachkar S, Redeker V and Sobel A: Stathmin family proteins display specific molecular and tubulin binding properties. J Biol Chem 276: 16146-16154, 2001.

14. Su D, Smith SM, Preti M, Schwartz P, Rutherford TJ, Menato G, Danese S, Ma S, Yu H and Katsaros D: Stathmin and tubulin expression and survival of ovarian cancer patients receiving platinum treatment with and without paclitaxel. Cancer 115: 2453-2463, 2009.

15. Watanabe A, Suzuki H, Yokobori T, Tsukagoshi M, Altan B, Kubo N, Suzuki S, Araki K, Wada S, Kashiwabara K, et al: Stathmin1 regulates p27 expression, proliferation and drug resistance, resulting in poor clinical prognosis in cholangiocarcinoma. Cancer Sci 105: 690-696, 2014.

16. Johnsen JI, Aurelio ON, Kwaja Z, Jögensen GE, Pellegata NS, Plattner R, Stanbridge EJ and Cajot JF: p53-mediated negative regulation of stathmin/Op18 expression is associated with G2/M cell-cycle arrest. Int J Cancer 88: 685-691, 2000.

17. Pang X, Yi T, Yi Z, Cho SG, Qu W, Pinkaew D, Fujise K and Liu M: Morelloflavone, a biflavonoid, inhibits tumor angiogenesis by targeting rho GTPases and extracellular signal-regulated kinase signaling pathways. Cancer Res 69: 518-525, 2009.

18. Li M, Li B, Xia ZM, Tian Y, Zhang D, Rui WJ, Dong JX and Xiao FJ: Anticancer Effects of Five Biflavonoids from Ginkgo Biloba L. Male Flowers In Vitro. Molecules 24: 1496, 2019.

19. Banerjee T, Valacchi G, Ziboh VA and van der Vliet A: Inhibition of TNFalpha-induced cyclooxygenase-2 expression by amentoflavone through suppression of NF-kappaB activation in A549 cells. Mol Cell Biochem 238: 105-110, 2002.

20. Zhang Z, Sun T, Niu JG, HeZQ, Liu Y and Wang F: Amentoflavone protects hippocampal neurons: Anti-inflammatory, antioxidative, and antiapoptotic effects. Neural Regen Res 10: 1125-1133, 2015.

21. An J, Li Z, Dong Y, Ren J and Huo J: Amentoflavone protects against psoriasis-like skin lesion through suppression of $\mathrm{NF}-\kappa \mathrm{B}-$ mediated inflammation and keratinocyte proliferation. Mol Cell Biochem 413: 87-95, 2016.

22. Li F, Song XW, Su GF, Wang YL, Wang ZY, Jia XY, Qin SR, Huang L, Wang Y, Zheng K and Wang Y: Amentoflavone inhibits HSV-1 and ACV-resistant strain infection by suppressing viral early infection. Viruses 11: 466, 2019.

23. Zhang J, Liu Z, Cao W, Chen L, Xiong X, Qin S, Zhang Z, Li X and Hu CA: Amentoflavone inhibits angiogenesis of endothelial cells and stimulates apoptosis in hypertrophic scar fifibroblasts. Burns 40: 922-929, 2014. 
24. Eshun-Wilson L, Zhang R, Portran D, Nachury MV, Toso DB Löhr T, Vendruscolo M, Bonomi M, Fraser JS and Nogales E: Effects of $\alpha$-tubulin acetylation on microtubule structure and stability. Proc Natl Acad Sci USA 116: 10366-10371, 2019.

25. Ohkawa N, Fujitani K, Tokunaga E, Furuya S and Inokuchi K: The microtubule destabilizer stathmin mediates the development of dendritic arbors in neuronal cells. J Cell Sc 120: 1447-1456, 2007.

26. Firsanov DV, Solovjeva LV and Svetlova MP: H2AX phosphorylation at the sites of DNA double-strand breaks in cultivated mammalian cells and tissues. Clin Epigenetics 2: 283-297, 2011.

27. Chen JJ, Silver DP, Cantor SB, Cantor S, Livingston DM and Scully R: BRCA1, BRCA2, and Rad51 operate in a common DNA damage response pathway. Cancer Res 59 (7 Suppl): 1752S-1756S, 1999.

28. Liu B and Yu S: Amentoflavone suppresses hepatocellular carcinoma by repressing hexokinase 2 expression through inhibiting JAK2/STAT3 signaling. Biomed Pharmacother 107: 243-253, 2018.

29. Lee KC, Tsai JJ, Tseng CW, Kuo YC, Chuang YC, Lin SS and Hsu FT: Amentoflavone inhibits ERK-modulated tumor progression in hepatocellular carcinoma in vitro. In Vivo 32: 549-554, 2018

30. Hsu FT, Chiang IT, Kuo YC, Hsia TC, Lin CC, Liu YC and Chung JG: Amentoflavone effectively blocked the tumor progression of glioblastoma via suppression of ERK/NF- $\mathrm{KB}$ signaling pathway. Am J Chin Med 47: 913-931, 2019.

31. Guruvayoorappan C and Kuttan G: Effect of amentoflavone on the inhibition of pulmonary metastasis induced by B16F-10 melanoma cells in C57BL/6 mice. Integr Cancer Ther 6: 185-197, 2007.

32. Lee JS, Lee MS, Oh WK and Sul JY: Fatty acid synthase inhibitionby amentoffflavone induces apoptosis and antiproliferation in human breast cancer cells. Biol Pharm Bull 32: 1427-1432, 2009.

33. Lee SJ, Kim HJ, Kang JW, Kim JH, Lee DH, Kim MS, Yang Y, Woo ER, Kim YM, Hong J and Yoon DY: The biflavonoid amentoflavone induces apoptosis via suppressing E7 expression, cell cycle arrest at sub-G1 phase, and mitochondria-emanated intrinsic pathways in Human Cervical Cancer Cells. J Med Food 14: 808-816, 2011

34. Pei JS, Liu CC, Hsu YN, Lin LL, Wang SC, Chung JG, Bau DT and Lin SS: Amentoflavone induces cell-cycle arrest and apoptosis in MCF-7 human breast cancer cells via mitochondria-dependent pathway. In Vivo 26: 963-970, 2012

35. Jung HJ, Park K, Lee IS, Kim HS, Yeo SH, Woo ER and Lee DG S-phase accumulation of Candida albicans by anticandidal effect of amentoflavone isolated from Selaginella tamariscina. Biol Pharm Bull 30: 1969-1971, 2007.

36. Liu H, Yue Q and He S: Amentoflavone suppresses tumor growth in ovarian cancer by modulating Skp2. Life Sci 189: 96-105, 2017.

37. Dehay $\mathrm{C}$ and Kennedy H: Cell-cycle control and cortical development. Nat Rev Neurosci 8: 438-450, 2007.

38. Malumbres $M$ and Barbacid M: Cell cycle, CDKs and cancer: A changing paradigm. Nat Rev Cancer 9: 153-166, 2009.

39. Marais A, Ji Z, Child ES, Krause E, Mann DJ and Sharrocks AD Cell cycle-dependent regulation of the forkhead transcription factor FOXK2 by CDK-cyclin complexes. J Biol Chem 285 : 35728-35739, 2010.

40. Bertoli C, Skotheim JM and de Bruin RA: Control of cell cycle transcription during G1 and S phases. Nat Rev Mol Cell Biol 14: 518-528, 2013

41. Choi WI, Kim MY, Jeon BN, Koh DI, Yun CO, Li Y, Lee CE, Oh J, Kim K and Hur MW: Role of promyelocytic leukemia zinc finger (PLZF) in cell proliferation and cyclin-dependent kinase inhibitor 1A (p21WAF/CDKN1A) gene repression. J Biol Chem 289: 18625-18640, 2014.

42. Tsuda $Y$, Iimori M, Nakashima $Y$, Nakanishi R, Ando K, Ohgaki K, Kitao H, Saeki H and Maehara Y: Mitotic slippage and the subsequent cell fate after inhibition of Aurora B during tubulin-binding agent-induced mitotic arrest. Sci Rep 17: 16762 , 2017.
43. Burbank KS and Mitchison TJ: Microtubule dynamic instability Curr Biol 16: R516-R517, 2006.

44. Benbow SJ, Wozniak KM, Kulesh B, Savage A, Slusher BS, Littlefield BA, Jordan MA, Wilson L and Feinstein SC: Microtubule-targeting agents eribulin and paclitaxel differentially affect neuronal cell bodies in chemotherapy induced peripheral neuropathy. Neurotox Res 32: 151-162, 2017.

45. Field JJ, Díaz JF and Miller JH: The binding sites of microtubule-stabilizing agents. Chem Biol 20: 301-315, 2013.

46. Cao YN, Zheng LL, Wang D, Liang XX, Gao F and Zhou XL: Recent advances in microtubule-stabilizing agents. Eur J Med Chem 143: 806-828, 2018.

47. Prota AE, Bargsten K, Zurwerra D, Field JJ, Diaz JF, Altmann KH and Steinmetz MO: Molecular mechanism of action of microtubule-stabilizing anticancer agents. Science 339: 587-590, 2013.

48. Cassimeris L: The oncoprotein 18/stathmin family of microtubule destabilizers. Curr Opin Cell Biol 14: 18-24, 2002.

49. Obayashi S, Horiguchi J, Higuchi T, Katayama A, Handa T, Altan B, Bai T, Bao P, Bao H, Yokobori T, et al: Stathmin1 expression is associated with aggressive phenotypes and cancer stem cell marker expression in breast cancer patients. Int J Oncol 51: 781-790, 2017.

50. Carney BK and Cassimeris L: Stathmin/oncoprotein 18, a microtubule regulatory protein, is required for survival of both normal and cancer cell lines lacking the tumor suppressor p53. Cancer Biol Ther 9: 699-709, 2010.

51. Alli E, Yang JM and Hait WN: Silencing of stathmin induces tumor-suppressor function in breast cancer cell lines harboring mutant p53. Oncogene 26: 1003-1012, 2007.

52. Wang R, Dong K, Lin F, Wang X, Gao P, Wei SH, Cheng SY and Zhang HZ: Inhibiting proliferation and enhancing chemosensitivity to taxanes in osteosarcoma cells by RNA interference-mediated downregulation of stathmin expression. Mol Med 13: 567-575, 2007

53. Dumontet $\mathrm{C}$ and Jordan MA: Microtubule-binding agents: A dynamic field of cancer therapeutics. Nat Rev Drug Discov 9: 790-803, 2010

54. Velic D, Couturier AM, Ferreira MT, Rodrigue A, Poirier GG, Fleury G and Masson GY: DNA damage signalling and repair inhibitors: The long-sought-after Achilles' heel of cancer. Biomolecules 5: 3204-3259, 2015.

55. Lobrich M, Shibata A, Beucher A, Fisher A, Ensminger M, Goodarzi AA, Barton O and Jeggo PA: GammaH2AX foci analysis for monitoring DNA double-strand break repair: Strengths, limitations and optimization. Cell Cycle 9: 662-669, 2010.

56. Daley JM, Kwon Y, Niu H and Sung P: Investigations of homologous recombination pathways and their regulation. Yale J Biol Med 86: 453-461, 2013

57. Graeser M, McCarthy A, Lord CJ, Savage K, Hills M, Salter J, Orr N, Parton M, Smith IE, Reis-Filho JS, et al: A marker of homologous recombination predicts pathologic complete response to neoadjuvant chemotherapy in primary breast cancer. Clin Cancer Res 16: 6159-6168, 2010.

58. Baumann P, Benson FE and West SC: Human Rad51 protein promotes ATP-dependent homologous pairing and strand transfer reactions in vitro. Cell 87: 757-766, 1996.

This work is licensed under a Creative Commons Attribution-NonCommercial-NoDerivatives 4.0 International (CC BY-NC-ND 4.0) License. 